\title{
Age of acquisition, not word frequency, affects object naming, not object recognition
}

\author{
CATRIONA M. MORRISON, ANDREW W. ELLIS, and PHILIP T. QUINLAN \\ University of York, York, England
}

\begin{abstract}
Word frequency is widely believed to affect object naming speed, despite several studies in which it has been reported that frequency effects may be redundant upon age of acquisition. We report, first, a reanalysis of data from the study by Oldfield and Wingfield (1965), which is standardly cited as evidence for a word frequency effect in object naming; then we report two new experiments. The reanalysis of Oldfield and Wingfield shows that age of acquisition is the major determinant of naming speed, and that frequency plays no independent role when its correlation with other variables is taken into account. In Experiment 1, age of acquisition and phoneme length proved to be the primary determinants of object naming speed. Frequency, prototypicality, and imageability had no independent effect. In Experiment 2, subjects classified objects into two semantic categories (natural or man-made). Prototypicality and semantic category were the only variables to have a significant effect on reaction time, with no effect of age of acquisition, frequency, imageability, or word length. We conclude that age of acquisition, not word frequency, affects the retrieval and/or execution of object names, not the process of object recognition. The locus of this effect is discussed, along with the possibility that words learned in early childhood may be more resistant to the effects of brain injury in at least some adult aphasics than words learned somewhat later.
\end{abstract}

Treatments of word retrieval in general, and object naming in particular, commonly propose that word frequency is an important determinant of the speed and accuracy of lexical access in speech production (e.g., Monsell, Doyle, \& Haggard, 1989; Riddoch \& Humphreys, 1987). It is widely accepted that the less frequent a word is in the English language, the slower one will be to name a pictorial representation of the object. The standard reference given in support of this assertion is Oldfield and Wingfield (1965), who reported an experiment in which 12 subjects named 26 line drawings of different objects. Oldfield and Wingfield found an inverse relationship between naming latency and frequency, such that the lower the frequency of a particular item (i.e., the less common its occurrence in English), the longer it took to name it. There are a number of reasons to be cautious about accepting the results of that study.

First, Oldfield and Wingfield (1965) failed to consider variables that correlate highly with frequency, such as length, imageability, and the age at which a word is acquired (age of acquisition). Second, they used the Thorndike-Lorge (1944) frequency count. This is an American word count drawn from school books and other similar reading material, and it may not have been a good index of the true frequency of word use by Oldfield and Wingfield's subjects ( 9 of the 12 of whom were under-

This study was conducted while Catriona Morrison was in receipt of a studentship from the Science and Engineering Research Council. Please address correspondence to A. Ellis, Department of Psychology, University of York, Heslington, York YOI 5DD, England. graduates or graduates at Oxford University). There is a further problem with the Thorndike-Lorge word list in that words of 50-100 occurrences per million are all given a single label (A), as are words with a value of $101+$ (AA), so that there is no way of discriminating within these categories, and the number assigned to words in the A and AA categories is to some degree arbitrary. That said, effects of frequency on object naming speed have since been reported by Huttenlocher and Kubicek (1983) and Humphreys, Riddoch, and Quinlan (1988).

Subsequent studies of object picture naming have broadened the range of variables whose possible effect on naming latency has been considered. Those variables include age of acquisition, codability (the proportion of responses which exactly match the target name), and word length (Carroll \& White, 1973b; Gilhooly \& Gilhooly, 1979; Lachman, 1973; Lachman, Shaffer, \& Hennrikus, 1974).

Age of acquisition scores for words are typically derived by asking subjects to use a rating scale to estimate the age at which they have learned a given word. Carroll and White (1973a) reported a correlation of 847 between rated age of acquisition and estimates of objective age of acquisition taken from studies of the frequency of word use in children's reading and writing. Gilhooly and Gilhooly (1980) found a correlation of .93 between rated age of acquisition and norms of a standardized vocabulary test (the Mill Hill test), and a correlation of .84 between rated age of acquisition and the ability of subjects of ages 5-21 to give acceptable definitions of those words. Age of acquisition ratings would thus seem to have reasonable validity. 
Age of acquisition correlates highly with other variables that have been held to affect word recognition and/or production. Gilhooly and Logie (1980) report a correlation of -.72 between age of acquisition and imageability, while age of acquisition has been reported to correlate at -.68 with frequency (Carroll \& White, 1973a), -.59 with concreteness, .56 with phoneme length, and .57 with letter length (Whaley, 1978). The size of these correlations will vary with the sample of words chosen (e.g., the correlation between age of acquisition and imageability is likely to be reduced in studies done with concrete nouns, owing to the restricted range of imageability values), but the fact that words acquired early in life tend to be short, concrete, and common means that age of acquisition needs to be taken into consideration as a potential confound when the effects of word length, imageability, and frequency are being investigated.

Our primary concerns here are whether word frequency or age of acquisition (or both) affects object naming, and at which information processing stage(s) those effects operate. Because of the high intercorrelations between frequency, age of acquisition, imageability, and length, it has not proved possible to devise sets of object pictures that would allow a factorial comparison of their effects. Hence, regression analyses have been employed in an attempt to tease apart their relative contributions. Carroll and White (1973b) carried out a picture naming experiment similar to Oldfield and Wingfield's (1965) but on a larger scale. They included as independent variables two measures of frequency taken from Thorndike-Lorge (1944) and Kučera and Francis (1967), two measures of age of acquisition (a mean rating given by 20 adults, and an objective rating derived from data concerning the scope of children's vocabulary), and two measures of word length (letters and syllables). They found that age of acquisition was the most significant variable in determining naming latency, and they found no effect of frequency when its correlation with age of acquisition and other factors was taken into account. Gilhooly and Gilhooly (1979) also found evidence of an age of acquisition effect on object naming speed, with word frequency being low on their list of independent variables in a stepwise regression analysis and well below significance.

In contrast, Lachman (1973) and Lachman et al. (1974) reported independent effects of age of acquisition, word length, and frequency on the naming of objects. Lachman et al. used 112 stimuli in their experiment and tested 16 subjects. Once the picture naming tests had been done, the same subjects were asked to give frequency and age of acquisition ratings for the 112 items. Objective ratings were also obtained, but in the regression analysis, individual ratings proved to be the best predictors of naming latency. Individual data points were used in the analyses. Lachman et al. report that while individual differences in reaction time (RT) are large, the relationship between reciprocal RT and the independent variables is robust. The Lachman et al. study is not without problems. In particular, when a subject made an incorrect response or a "late response," or caused the voice key to misfire, the experimenter estimated how long it would have taken the subject to name the item if none of those errors had occurred. The range of estimated responses for subjects ranged from 0 to 24 of 112 responses.

There thus remains some uncertainty about whether word frequency does or does not influence object naming speed as Oldfield and Wingfield (1965) claimed. Fortunately, Oldfield and Wingfield reported the mean latencies across subjects for each item in their study. This makes it possible to reanalyze their findings in the light of more recent work, using additional independent variables.

\section{REANALYSIS OF THE OLDFIELD AND WINGFIELD DATA}

\section{Method}

Cohen and Cohen (1975) suggest that reciprocal transformations are more appropriate when one is dealing with RT data. They point out that in cases in which there is no time limit on response, if subjects' scores are expressed as rates, the result is $1 / t$ (that is, the reciprocal of the varying times taken to respond to items across subjects). Thus if a variable $v$ were linearly related to rate, $v$ would be linearly related to $1 / t$. Such transforms have been used in other similar experiments (e.g., Carroll \& White, 1973b; Gilhooly \& Gilhooly, 1979). The dependent variable used here is a reciprocal transformation of Oldfield and Wingfield's (1965) latency values. This variable has been termed naming speed. The independent variables included in the reanalysis were frequency, age of acquisition, and length (number of phonemes). ${ }^{1}$

Frequency values were taken from Kučera and Francis (1967). Only the singular forms of words were taken from Kučera and Francis's count, and $a \log (1+x)$ transform was computed on the frequency values in order to reduce skew. This technique is very commonly used with frequency data, because of their tendency to be highly negatively skewed (e.g., Carroll \& White, 1973b; Lachman, 1973; Oldfield \& Wingfield, 1965). Age of acquisition ratings were taken from the MRC Psycholinguistic Database (Quinlan, 1992). Correlation analyses were carried out on the data in order to determine whether the frequency effect found by Oldfield and Wingfield (1965) held with the new frequency measure, and whether any of the other variables had an impact on naming speed.

\section{Results and Discussion}

A matrix of intercorrelations among all the variables is shown in Table 1. Naming speed correlates very highly with age of acquisition and word length. The correlation of naming speed with frequency is the lowest, although it is still significant. Frequency also correlates significantly with age of acquisition and length. This confirms doubts mentioned earlier in connection with Oldfield and Wing-

Table 1

Correlation Matrix of the Relationships Among the Dependent Variable (Naming Speed) and the Independent Variables for Oldfield and Wingfield's (1965) Data

\begin{tabular}{lcccc}
\hline & 1 & 2 & 3 & 4 \\
\hline 1. Naming speed & 1.00 & $.69^{*}$ & $-.83^{*}$ & $-.75^{*}$ \\
2. Log frequency & & 1.00 & $-.73^{*}$ & $-.66^{*}$ \\
3. Age of acquisition & & & 1.00 & $.76^{*}$ \\
4. Word length (phonemes) & & & & 1.00 \\
\hline
\end{tabular}


Table 2

Multiple Regression Analysis of the Oldfield and Wingfield

(1965) Data With Naming Speed as the Dependent Variable

\begin{tabular}{lccccc}
\hline & $\beta$ & & Standard & \\
& Coefficient & $S E$ & Coefficient & $t$ Value & $p$ \\
\hline Age of acquisition & -.091 & .031 & -.571 & 2.95 & $.007^{*}$ \\
Length & -.033 & .024 & -.238 & 1.36 & .19 \\
Log frequency & .055 & .082 & .112 & .67 & .51 \\
\hline${ }^{*} p<.01$. & & & & &
\end{tabular}

field's (1965) failure to examine other variables that have significant correlations with frequency.

The data were then examined with regression analyses. A multiple regression analysis produced $R=.85(p<$ .0001 ) for the combined effects of age of acquisition, frequency, and length on picture naming speed. As can be seen in Table 2 , the only statistically significant variable is age of acquisition. Neither length nor frequency approached statistical significance.

These conclusions are supported by a stepwise regression. Unlike multiple regression, in which all the variables enter the equation in a single sweep, stepwise regression involves entering variables into the equation one at a time. It is, in effect, a series of separate multiple regression analyses. Using $F$ tables, for $d f=1,25, F$-toenter is set at 4.24. The only variable to enter the equation with $F$-to-enter at 4.24 is age of acquisition $(F=$ $54.69, p<.01$ ). Once again, neither length nor frequency came close to significance. This confirms the importance of age of acquisition in picture naming and casts further doubt on the role of frequency.

The results show that the frequency effect found by Oldfield and Wingfield (1965) was artifactual; frequency is subsumed by the more important variable of age of acquisition and in fact makes no independent contribution to the time it takes to name a picture. We note that neither Huttenlocher and Kubicek (1983) nor Humphreys et al. (1988) controlled for age of acquisition when claiming an effect of word frequency on object naming speed.

\section{COGNITIVE MODELS OF OBJECT NAMING}

Discovering that particular variables affect the speed of object naming is important, but the experiments described above leave us short of an understanding of where within the total cognitive system those variables are exerting their effects. Current accounts of object recognition and naming identify several information processing stages (or representations) between the physical object and the spoken name (Humphreys \& Riddoch, 1987; Seymour, 1979; Theios \& Amrhein, 1989). These models are held to account for both experimental data from cognitive psychological studies and neuropsychological data on patterns of breakdown of object recognition and naming in brain-injured patients (Ellis \& Young, 1988; Farah, 1990; Humphreys et al., 1988). For the present purposes, these operations can be simplified into the three stages outlined in Figure 1.
If an object or picture is to be named successfully, it must first undergo perceptual analysis to generate an internal representation of the object's visual features and their relations to one another. If the object is a familiar one, that perceptual description will activate one of a set of long-standing visual representations that encode the appearance of familiar objects. The stage of object recognition in Figure 1 subsumes all of these perceptual operations. Once an object has been identified as familiar, the next stage involves activating stored representations in a semantic system in which knowledge about object properties is held (e.g., how to use a telephone; whether a particular berry is edible or not). Finally, the spoken word-form that is the object's name must be accessed within a phonological lexicon and that word-form must ultimately be converted into a sequence of articulatory commands. These processes are depicted in Figure 1 as involving phonological representations.

In the present paper, we report two experiments aimed at clarifying which variables affect object naming and where those variables exert their influence. In Experiment 1 , we took a fresh look at determinants of naming speed and considered frequency, age of acquisition, word length, imageability, and prototypicality as potentially important factors. In Experiment 2, we used the pictures from Experiment 1, but this time subjects were required to classify each object as natural or man-made. This distinction was chosen on the grounds that if the natural objects include such things as fish, trees, and fruits, their classification as being natural or man-made cannot be reli-

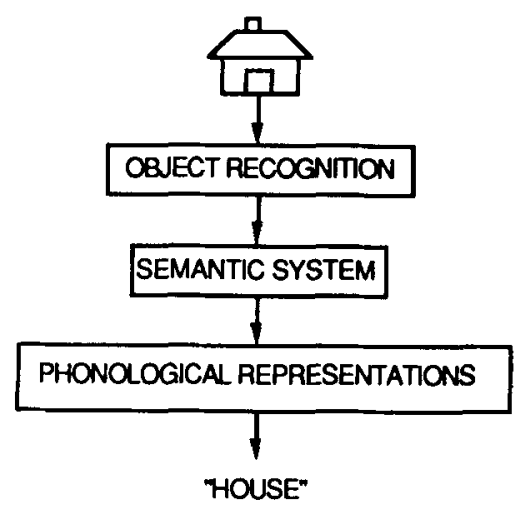

Figure 1. A simple model of the processes involved in picture naming. 
ably achieved through responding to the presence or absence of simple visual features such as eyes or legs (cf. Lupker, 1985). In terms of the theoretical account of object naming in the previous section, the semantic classification task in Experiment 2 required successful object recognition and the activation of appropriate representations in the semantic system. It did not require phonological representations to be accessed. In Experiment 1, in contrast, all three stages had to be successfully traversed. If a given variable affects both naming (Experiment 1) and semantic classification (Experiment 2), that variable may be influencing either object recognition or semantic access. If a variable affects naming but not semantic classification, its locus of influence is presumed to be at the level of phonological representations.

\section{EXPERIMENT 1 Object Picture Naming}

\section{Method}

Subjects. The subjects were 20 psychology undergraduate students at the University of York. Each was paid $£ 1$ or given a course credit for taking part.

Design and Materials. The stimuli were a set of 58 line drawings taken from Snodgrass and Vanderwart (1980). The items were selected to fall into two broad categories-man-made objects and naturally occurring objects. This distinction was made for the purposes of obtaining a prototypicality score and of conducting a picture categorization experiment (Experiment 2). The variables looked at were frequency, age of acquisition, prototypicality, word length, and imageability. Sets were matched across categories on all the variables, so that both categories had similar means, standard deviations, minima, maxima, and ranges for each variable.

Ratings for the items on a measure of prototypicality were obtained by using the categories natural and man-made (see Experiment 2). Twelve independent subjects were given a list of the names of the objects used in Experiments 1 and 2. The instructions closely followed Hampton and Gardiner (1983). The subjects rated the names of the objects used in Experiments 1 and 2 on a scale from 1 to 5 , where 1 represents a very atypical instance of the category natural or man-made, and 5 represents a very typical instance. The mean ratings for each item over the 12 subjects were calculated to obtain a prototypicality score for each item.

The frequency measure was again that from Kučera and Francis (1967). ${ }^{2}$ Only singular items were used as data. The data was transformed using a $\log (1+x)$ transform to correct skew. Age of acquisition ratings were taken from Carroll and White's (1973a) study, in which 62 subjects were asked to rate the age at which they believed they had learned 220 pictureable nouns on a 9-point scale from $1=$ learned at age 2 to $9=$ learned at ages $13+$. A measure of imageability - how easily a word arouses a mental image-was taken from the MRC psycholinguistic database (Quinlan, 1992). Values on this variable were all high and the range was small (.91 on a scale of 1-7). This, however, is bound to be the case with a set of stimuli that are of necessity concrete. Word length was measured as the number of phonemes in a name.

Procedure. The experiment was conducted on a Macintosh SE/30 computer, using the Psychlab package (Bub \& Gum, 1990). A fixation dot was shown for $500 \mathrm{msec}$ before each stimulus was presented. Response timing began at the onset of the stimulus. When a response was made, it was picked up by a high-sensitivity microphone attached to the subject's collar, which triggered a voice key. There was then an interval of 500 msec before the next fixation dot appeared, followed 500 msec later by the next item.

The items were presented to all 20 subjects in a fixed, random order. The following instructions were given to the subjects:

This is an experiment to see how quickly people name objects. You will be shown a series of line drawings of different objects. It is your task to name these objects, clearly and loudly, as quickly as possible. Try not to say "um" or make any other verbal hesitations, as this will be taken as a response by the computer and it will show you the next object. If you name an object incorrectly, don't worry about it or try to correct yourself, just go on with the next item. Remember to speak clearly and loudly and to respond as quickly as possible.

The 58 test trials were preceded by 6 practice trials with the items pear, aeroplane, pan, owl, hand, and paintbrush, in order to familiarize the subjects with the procedure. If, at the end of the practice trials, subjects felt they were ready to begin the experiment proper, the test trials began. If not, they were shown the practice items a second time so that they were sure of the task requirements before the experiment proper began. While subjects were naming the objects, the experimenter noted down any verbal hesitations that caused the voice key to misfire or any deviations in naming from the exact target.

\section{Results and Discussion}

Ten items had high error scores: accordion (50\%), bear (35\%), bee $(70 \%)$, broom $(30 \%)$, caterpillar $(25 \%)$, com $(65 \%)$, leopard $(30 \%)$, peach $(40 \%)$, potato $(25 \%)$, and turtle $(65 \%)$. Removing these 10 items from the data reduced the error rate from $9.1 \%$ to $3.2 \%$. The mean time taken to name each of the remaining 48 items over the 20 subjects was then calculated. The 48 items used and their values on the independent variables are shown in the Appendix. The mean time taken to name the 48 pictures was 792 msec.

Naming latencies were once again transformed to their reciprocals to reduce negative skew. Table 3 shows the intercorrelations between the dependent variable, naming speed, and the five independent variables. The variable that correlates most highly with naming speed is length, followed by age of acquisition and then frequency. None of the other independent variables have significant correlations with naming speed. It is also important to note

Table 3

Correlation Matrix for All the Variables in Experiment 1

\begin{tabular}{lcccccc}
\hline & 1 & 2 & 3 & 4 & 5 & 6 \\
\hline 1. Naming speed & 1.00 & $.29^{*}$ & $-.40 \dagger$ & $-.43 \dagger$ & -.05 & .08 \\
2. Log frequency & & 1.00 & $-.38 \dagger$ & $-.44 \dagger$ & -.08 & .17 \\
3. Age of acquisition & & & 1.00 & $.34^{*}$ & $-.29^{*}$ & $-.38 \dagger$ \\
4. Length & & & & 1.00 & -.04 & -.09 \\
5. Imageability & & & & & 1.00 & .12 \\
6. Prototypicality & & & & & & 1.00 \\
\hline
\end{tabular}

${ }^{*} p<.05 . \quad \dagger_{p}<.01$. 
Table 4

Multiple Regression for Data from Experiment 1

(Picture Naming)

\begin{tabular}{lccccc}
\hline & $\begin{array}{c}\beta \\
\text { Coefficient }\end{array}$ & $S E$ & $\begin{array}{c}\text { Standard } \\
\text { Coefficient }\end{array}$ & $t$ Value & $p$ \\
\hline Age of acquisition & -.063 & .028 & -.362 & 2.23 & $.03^{*}$ \\
Length & -.031 & .015 & -.315 & 2.13 & $.04^{*}$ \\
Imageability & -.094 & .085 & -.154 & 1.10 & .28 \\
Prototypicality & -.018 & .038 & -.068 & .48 & .63 \\
Log frequency & .004 & .044 & .014 & .09 & .93 \\
\hline
\end{tabular}

$p<.05$.

the high intercorrelations among some of the independent variables: frequency and length correlate highly, as do frequency and age of acquisition. Age of acquisition also has high correlations with prototypicality, length, and imageability.

The first analysis carried out was a multiple regression analysis on all the variables. The results are shown in Table 4 . The overall equation produced $R=.536(p=.01)$. Two predictor variables stand out as having significant independent effects: age of acquisition and word length. There is no trace of an effect of word frequency.

Stepwise regression analyses confirmed this finding. In the conventional manner, the first stepwise analysis entered the independent variables in the order of their simple correlations with naming speed. When this was done, only word length $\left(R^{2}=.19, F=10.5, p<.01\right)$ and age of acquisition $\left(R^{2}=.26, F=7.92, p<.01\right)$ attained significance. In a supplementary analysis, frequency was forced into the stepwise regression as the first variable. This time, the effect of frequency was significant $\left(R^{2}=\right.$ $.09, F=4.3, p<.05$ ), but so were the effects of length $\left(R^{2}=.26, F=5.2, p<.05\right)$ and age of acquisition $\left(R^{2}=.18, F=5.1, p<.05\right)$. That is, length and age of acquisition continued to exert independent effects on naming speed even after all of the variance due to word frequency had been partialed out, whereas word frequency had no independent effect after the variance due to length and age of acquisition had been partialed out. This implies that apparent frequency effects may be reducible to age of acquisition and length effects, but that the converse is not true.

The results of Experiment 1 replicate the studies of Carroll and White (1973b), Lachman (1973), Lachman et al. (1974), and Gilhooly and Gilhooly (1979) in the finding of an effect of age of acquisition on object naming speed. They also agree with Carroll and White (1973b), Gilhooly and Gilhooly (1979), and our reanalysis of Oldfield and Wingfield (1965) in the finding of no independent contribution of word frequency (contra Lachman, 1973, and Lachman et al., 1974). The lack of an effect of imageability accords with Gilhooly and Gilhooly's (1979) finding that concreteness (a closely related variable) had no effect on object naming speed. Only Carroll and White (1973b) have previously included word length as a factor. They found no significant effect of word length on naming speed, but their measures were letter length and number of syllables rather than number of phonemes as employed here. We note, though, that no effect of length was found in the reanalysis of Oldfield and Wingfield (1965) presented above.

Wingfield (1968) followed the discovery by Oldfield and Wingfield (1965) of an apparent frequency effect in object naming by an attempt to characterize more precisely the locus of that effect. He found no effect of frequency on the time taken to judge whether a visually presented object matched a heard object name and only a small effect of frequency on the exposure duration required to identify objects (tachistoscopic visual duration threshold). We note that tachistoscopic identification requires name retrieval and that objects with high- and lowfrequency names will also tend to differ on familiarity. Bartram (1976) found no effect of name frequency on the time taken to match pairs of object pictures as physically identical or different.

On balance, the available evidence does not suggest that name frequency affects the time taken to recognize objects. We have argued that apparent effects of frequency on naming latency are actually age of acquisition effects. In Experiment 2, we examined the possible effects of age of acquisition, frequency, and other variables on the time taken to classify objects into the semantic categories natural or man-made. As far as we are aware, previous researchers have not looked for effects of age of acquisition on object recognition as distinct from object naming.

\section{EXPERIMENT 2 Picture Categorization}

\section{Method}

Subjects. The subjects were $\mathbf{2 0}$ undergraduate or postgraduate students at the University of York. Each was paid $f 1$, or given a course credit for taking part.

Design and Materials. The materials were the same set of 48 line drawings that were found to elicit acceptably high naming accuracy in Experiment 1 . The objects had been chosen at the outset with the aim of doing a semantic categorization experiment. The original 58 drawings were split evenly between two categories: manmade and naturally occurring. These categories were chosen in an attempt to minimize the extent to which simple visual features could be used as a reliable basis for classification. Thus, in the man-made category there were items such as ball and cake (which do not conform to the cues of straight lines and sharp edges that one might suggest are used in discriminating man-made objects); and in the naturally occurring set there were items such as lemon and apple, 
which are visually more similar to ball and cake than they were to other items in their own set such as elephant and tree. Because some items were eliminated after the first experiment had been conducted, 27 man-made objects and 21 naturally occurring objects were employed in Experiment 2.

As before, the variables of interest were $\log (1+x)$ frequency, age of acquisition, word length, imageability, and prototypicality. Category ( 1 = man-made; 0 = naturally occurring) was added as an additional independent variable to the analysis of Experiment 2.

Procedure. The equipment from Experiment 1 was employed here, but instead of making a voice-key response, subjects responded by using yes/no keys, placing their left hand on the yes and their right hand on the no. A fixation dot appeared on the screen for $200 \mathrm{msec}$; this was followed by the stimulus. The subjects were instructed to respond "yes" if they thought the object was manmade and "no" if they thought it was not man-made (i.e., was naturally occurring). The instructions to the subjects were as follows:

This is an experiment to see how quickly people can categorize objects. You will be shown a series of line drawings of different objects. It is your task to categorize them as quickly as you can. There are two categories: man-made, and not man-made. If you think an object is man-made, press the "yes" key, and if it is not man-made, press the "no" key. Try to respond as quickly as possible because this is a test of your reaction time. Try to respond as accurately as possible, but if you make a mistake don't worry about it or try to correct it, simply go on with the next item.

When a response was made there was an intertrial interval of 1,000 msec before the next fixation dot appeared on the screen.

The subjects were given the opportunity to familiarize themselves with the yes/no keys before the practice trials began. The practice items consisted of the line drawings of eight man-made objects and eight objects presented in a random order; they were: bed, spider, bread, telephone, carrot, saw, fox, orange, car, arm, shoe, cigar, grapes, snail, piano, and nose. If subjects did not feel comfortable with the task once they had completed the practice session, they were given the items again. If they felt comfortable with the task, they began the experiment proper. The 48 test items were randomized by the computer before the experiment began, and all 20 subjects saw them in this order. A note was taken of any accidental pressing of the keys, and the computer recorded the responses, so that they could be checked afterward to see whether they were correct or not. All incorrect responses were removed from the analyses.

\section{Results and Discussion}

The error rate across subjects for all 48 items was $3.1 \%$. Mean response latencies over the 20 subjects were transformed using a $\log (1+x)$ transform in order to reduce skew. Categorization speed was the dependent variable.

Table 5 shows the correlation matrix for all variables. Because the same items were used in the object naming experiment as were used here, the values for the independent variables - and therefore the strengths of their correlations-are the same as in Table 3. The important row here is the first one, which shows the intercorrelations between the dependent variable and the independent variables. Category and prototypicality correlate significantly with categorization speed. Age of acquisition, frequency, imageability, and word length have no effect on categorization speed.

When a multiple regression analysis was done, the overall equation only approached significance $(R=.484, p=$ $.08)$. However, upon closer inspection, it would appear that category and prototypicality had effects on categorization speed (see Table 6). The relation between categorization speed and category was significant, as was the relation between categorization speed and prototypicality. None of the other variables are close to significance, and age of acquisition, at $p=.25$, certainly does not play a part in semantic classification of objects.

This result was checked by using stepwise regression. Only category $\left(R^{2}=.134, F=7.10, p<.05\right)$ and prototypicality $\left(R^{2}=.207, F=5.89, p<.05\right)$ attained significance. Imageability, age of acquisition, frequency, and word length were well below the required $F$-to-enter level.

Table 5

Correlation Matrix for All the Variables in Experiment 2

\begin{tabular}{lccccccc}
\hline & 1 & 2 & 3 & 4 & 5 & 6 & 7 \\
\hline 1. Categorization speed & 1 & -.005 & -.06 & -.04 & .2 & $.29^{*}$ & $-.37^{*}$ \\
2. Log frequency & & 1 & $-.38 \dagger$ & $-.44 \dagger$ & -.08 & .17 & .14 \\
3. Age of acquisition & & & 1 & $.34^{*}$ & $-.29 *$ & $-.38 \dagger$ & .26 \\
4. Length & & & 1 & -.04 & -.09 & .03 \\
5. Imageability & & & & 1 & .12 & $-.57 \dagger$ \\
6. Prototypicality & & & & & 1 & -.06 \\
7. Category & & & & & & \\
\hline$p<.05 . \quad \dagger p<.01$.
\end{tabular}

Table 6

Multiple Regression for Data in Experiment 2 (Semantic Categorization)

\begin{tabular}{lccccc}
\hline & $\begin{array}{c}\beta \\
\text { Coefficient }\end{array}$ & $S E$ & $\begin{array}{c}\text { Standard } \\
\text { Coefficient }\end{array}$ & $t$ Value & $p$ \\
\hline Category & -.157 & .065 & -.414 & 2.43 & $.02^{*}$ \\
Prototypicality & .114 & .051 & .334 & 2.25 & $.03^{*}$ \\
Age of acquisition & .044 & .038 & .2 & 1.16 & .25 \\
Log frequency & .021 & .06 & .057 & .35 & .73 \\
Length & -.005 & .02 & -.037 & .24 & .81 \\
Imageability & -.012 & .131 & -.015 & .09 & .93 \\
\hline
\end{tabular}

${ }^{*} p<.05$. 
Howell (1982) provides a formula for testing the difference between the effects of the same independent variable in two separate regression analyses. ${ }^{3}$ When simple regressions are computed to plot the relationships between age of acquisition and naming speed and between age of acquisition and categorization speed, the figures are $R=$ .403 for picture naming and $R=.06$ for semantic categorization ( $N=48$ for both experiments); this produces a value of $z=1.64, p<.05$. This suggests that the effect of age of acquisition on the dependent variable was significantly smaller in Experiment 2 (categorization) than in Experiment 1 (naming).

The absence of any hint of an effect of age of acquisition or word length on semantic categorization supports the claim that those variables exert their influence at the stage of name retrieval. We regard that as the main lesson of Experiment 2. It remains to be explained, though, how prototypicality could affect categorization but not naming. By the account given above, a variable that affects an early stage of processing should affect all other tasks that involve that stage. If prototypicality affects either the perceptual identification of objects or the accessing of their semantic representations, it should also affect naming speed. In attempting to explain this finding, one might argue that when a subject is required to classify objects as natural or man-made (as in Experiment 2), there is a stage after the accessing of semantic knowledge that involves deciding which of the two experimentally specified categories an object belongs in. "Naturalness versus man-madeness" might not be part of an object's intrinsic semantic representation and may need to be deduced from that representation. That postsemantic decision may be made more quickly for prototypical exemplars than for nonprototypical exemplars.

\section{GENERAL DISCUSSION}

Experiment 1, combined with the reanalysis of Oldfield and Wingfield (1965), clearly shows that age of acquisition rather than word frequency affects object naming speed. This is in line with the previous findings of Carroll and White (1973b) and Gilhooly and Gilhooly (1979). Neither those papers nor the present experiments support the claim of Lachman (1973) and Lachman et al. (1974) that there is an effect of word frequency over and above the age of acquisition effect. The lack of an effect of age of acquisition in semantic categorization found in Experiment 2 indicates that age of acquisition affects name retrieval/production rather than object recognition or comprehension. Loftus and Suppes's (1972) report of an effect of age of acquisition on the time taken to generate words in response to a category label and initial letter cue (e.g., fruit $+p \rightarrow$ plum) is compatible with this claim.

It has been argued that word frequency affects other aspects of word retrieval in normal subjects. Highfrequency words have, for example, been reported to be relatively immune to involvement in speech errors (Kelly, 1986; Stemberger \& MacWhinney, 1986). Vitkovitch and
Humphreys (1991) induced perseverative picture naming errors in the laboratory and found that errors were more common to low- than high-frequency target names. However, none of these studies were used to determine whether frequency or age of acquisition is in fact the crucial variable. On the basis of what appears to be true for object naming latencies, we would suggest that all of these effects may in reality be age of acquisition rather than word frequency effects. Studies of the supposed effects of word frequency on the latency to name written words (e.g., McRae, Jared, \& Seidenberg, 1990; Monsell et al., 1989) continue to appear, despite the fact that all three of the studies in which the contributions of frequency and age of acquisition to word naming have been compared have shown frequency to be redundant upon age of acquisition (Brown \& Watson, 1987; Gilhooly \& Logie, 1981; Rubin, 1980). It is not at all clear that word frequency makes any independent contribution to word naming latency once its correlation with age of acquisition is allowed for.

It has also been argued that word frequency is an important determinant of success in name retrieval among brain-injured aphasic patients. Studies of the performance of groups of aphasic patients (Howard, Patterson, Franklin, Orchard-Lisle, \& Morton, 1984; Howes, 1967; Rochford \& Williams, 1965; and many others) and of single patients (e.g., Ellis, Miller, \& Sin, 1983; Kay \& Ellis, 1987; Miceli, Giustolisi, \& Caramazza, 1991; Zingeser \& Berndt, 1988) have indicated that high-frequency words survive brain injury better than low-frequency. Again, in these studies, researchers have typically failed to consider the possibility that age of acquisition rather than word frequency may be the important variable. Rochford and Williams (1962) found that the age at which an object could be named by $80 \%$ of children was a good predictor of the number of aphasic patients able to name that object. Spreen and Benton (cited in Spreen, 1968) found that aphasic accuracy in naming 40 common objects correlated .86 with age of acquisition in children of the ages 2-13 years, and Hirsh (1992) reports an analysis of the naming of a single aphasic patient whose accuracy was affected by age of acquisition rather than word frequency. A genuine role for word frequency is, however, suggested by the results of Feyereisen, van der Borght, and Seron (1988), who tested the ability of 18 aphasic subjects to name 64 stimuli and found that age of acquisition and word frequency independently predicted the proportion of aphasic subjects able to name an item. The relative contributions of age of acquisition and word frequency to aphasic performance warrant further investigation.

We have argued that the age of acquisition effect resides in the retrieval and/or execution of phonological word-forms. That leaves several explanatory options open. One possibility is that age of acquisition affects the strength of connections between semantic and phonological representations. This would be in line with connectionist (or connectionist-inspired) accounts of word frequency effects (see Monsell, 1991), but in this version, words acquired early in life would form stronger connec- 
tions between semantic and phonological representations than would words acquired later.

Another possibility is that age of acquisition reflects an intrinsic property of phonological representations. Gilhooly and Gilhooly (1979) and Gilhooly and Watson (1981) offered an account of age of acquisition in terms of the logogen model of Morton (1969; Morton \& Patterson, 1980) in which words are represented in a speech output lexicon as units called logogens, suggesting that logogens corresponding to earlier acquired words have lower thresholds. Brown and Watson (1987) suggested that

Phonological output representations are stored in a relatively complete form during the early stages of vocabulary acquisition. As vocabulary size increases, storage limitations require more efficient strategies, and only minimal information is stored explicitly.... The phonological information that is not directly represented has to be generated whenever required. This takes time, and this is reflected in word naming latency. (pp. 214-215)

Current models of visual word recognition (e.g., McClelland \& Rumelhart, 1985; Morton \& Patterson, 1980; Theios \& Amrhein, 1989) propose a direct mapping between orthography and phonology, which functions in parallel with the mapping from orthography to semantics. Such accounts propose that rapid word naming involves direct mapping between orthography and phonology and does not engage the connections between semantic and phonological representations. Hence, if a common locus is wanted for age of acquisition effects in word and object naming, having those effects arise out of the intrinsic structure of phonological representations themselves might provide the most parsimonious explanation. Whatever theoretical account is ultimately given, it seems clear that representations of spoken word-forms that are established relatively early in life remain more accessible thereafter and may be more resistant to the effects of subsequent damage.

\section{REFERENCES}

Bartram, D. I. (1976). Levels of coding in picture-picture comparison tasks. Memory \& Cognition, 4, 593-602.

Brown, G. D. A., \& WATSON, F. L. (1987). First in, first out: Word learning age and spoken word frequency as predictors of word familiarity and word naming latency. Memory \& Cognition, 15, 208-216.

Bub, D., \& Gum, T. (1990). Psychlab (Version 0.85) [Computer program]. (available from D. Bub, 3815 Oxford Ave. Montreal, PQ H4A 2Y3, Canada)

Carroll, J. B., W Wite, M. N. (1973a). Age of acquisition norms for 220 pictureable nouns. Journal of Verbal Learning \& Verbal Behavior, 12, 563-576.

Carroll, J. B., \& Wite, M. N. (1973b). Word frequency and ageof-acquisition as determiners of picture-naming latency. Quarterly Journal of Experimental Psychology, 25, 85-95.

COHEN, J., COHEN, P. (1975). Applied multiple regression/correlation analysis for the behavioral sciences. Hillsdale, NJ: Erlbaum.

Elus, A. W., Miller, D., \& SiN, G. (1983). Wernicke's aphasia and normal language processing: A case study in cognitive neuropsychology. Cognition, 15, 111-144.

Elus, A. W., \& Young, A. W. (1988). Human cognitive neuropsychology. Hove, U.K.: Erlbaum.

FARAH, M. J. (1990). Visual agnosia: Disorders of vision and what they tell us about normal object recognition. Cambridge, MA: MIT Press/Bradford Books.

Feyereisen, P., VAN der Borght, F., Seron, X. (1988). The operativity effect in naming: A reanalysis. Neuropsychologia, 26, 401-415.

Gilhoоly, K. J., \& GilHoOLy, M. L. (1979). Age-of-acquisition effects in lexical and episodic memory tasks. Memory \& Cognition, 7 , 214-223.

Gilhooly, K. J., \&ilhooly, M. L. (1980). The validity of age of acquisition ratings. British Journal of Psychology, 71, 105-110.

GILHOOLY, K. J., LOGIE, R. H. (1980). Age-of-acquisition, imagery, concreteness, familiarity, and ambiguity measures for 1,944 words. Behavior Research Methods \& Instrumentation, 12, 395-427.

GILHOOLY, K. J., \& LOGIE, R. H. (1981). Word age-of-acquisition, reading latencies and auditory recognition. Current Psychological Research, 1, 251-262.

GilhoOLY, K. J., \& WATSON, F. L. (1981). Word age-of-acquisition effects: A review. Current Psychological Research, 1, 269-286.

HAmpton, J. A., GARDiner, M. M. (1983). Measures of internal category structure: A correlational analysis of normative data. British Joumal of Psychology, 74, 491-516.

HiRSH, K. W. (1992). Age of acquisition and naming. Proceedings of the Bonn conference on the evaluation of the efficacy of technology in the assessment and rehabilitation of brain-damaged patients. Bonn.

Howard, D., Patterson, K. E., Frankuin, S., Orchard-Lisle, V. M., MORTON, J. (1984). Variability and consistency in picture naming by aphasic patients. In F. C. Rose (Ed.), Advances in neurology: Vol. 42. Progress in aphasiology (pp. 263-276). New York: Raven Press.

Howel., D. (1982). Statistical methods for psychology. Boston: Duxbury Press.

Howes, D. (1967). Some experimental investigations of language in aphasia. In K. Saltzinger \& S. Saltzinger (Eds.), Research in verbal behaviour and some neurophysiological implications (pp. 189-196). New York: Academic Press.

Humphreys, G. W., \& RidDoch, M. J. (1987). Picture naming. In G. W. Humphreys \& M, J. Riddoch (Eds.), Visual object processing: A cognitive neuropsychological approach (pp. 107-143). London: Erlbaum.

Humphreys, G. W., RidDoch, M. J., Q Quinlan, P. T. (1988). Cascade processes in picture identification. Cognitive Neuropsychology, $5,67-103$.

HutTenlocher, J., \& KUBiceK, L. F. (1983). The source of related ness effects on naming latency. Journal of Experimental Psychology: Learning, Memory, \& Cognition, 9, 486-496.

Johansson, S., \& Hofland, K. (1989). Frequency analysis of English vocabulary and grammar (Vol. 1). Oxford: Oxford University Press/Clarendon Press.

KAY, J., \& ELLIS, A. W. (1987). A cognitive neuropsychological case study of anomia. Brain, 110, 613-629.

KeLLY, M. H. (1986). On the selection of linguistic options. Unpub lished doctoral dissertation, Cornell University.

KuCERA, H., \& FrANCIS, W. (1967). Computational analysis of presentday American English. Providence, RI: Brown University Press.

LACHMAN, R. (1973). Uncertainty effects on time to access the internal lexicon. Journal of Experimental Psychology, 99, 199-208.

Lachman, R., Shaffer, J. P., \& Hennrikus, D. (1974). Language and cognition: Effects of stimulus codability, name-word frequency, and age of acquisition on lexical RT. Journal of Verbal Learning \& Verbal Behavior, 13, 613-625.

LofTus, E. F., \& SuPPEs, P. (1972). Structural variables that determine the speed of retrieving words from long-term memory. Journal of Verbal Learning \& Verbal Behavior, 11, 770-777.

LUPKER, S. J. (1985). Context effects in word and picture recognition: A re-evaluation of structural models. In A. W. Ellis (Ed.), Progress in the psychology of language (Vol. 1, pp. 109-142). London: Erlbaum.

MCClelland, J. L., Rumelhart, D. E. (1985). Distributed memory and the representation of general and specific information. Journal of Experimental Psychology: General, 114, 159-188.

MCRae, K., JARed, D., Seidenberg, M. S. (1990). On the roles of frequency and lexical access in word naming. Journal of Memory \& Language, 29, 43-65.

Micel, G., Giustolisi, L., \& Caramazza, A. (1991). The interaction 
of lexical and non-lexical processing mechanisms: Evidence from aphasia. Cortex, 27, 57-80.

MONSELL, S. (1991). The nature and locus of word frequency effects in reading. In D. Besner \& G. W. Humphreys (Eds.), Basic processes in reading: Visual word recognition (pp. 148-197). Hillsdale, NJ: Erlbaum.

Monsell, S., Doyle, M. C., Haggard, P. N. (1989). Effects of frequency on visual word recognition tasks: Where are they? Journal of Experimental Psychology: General, 118, 43-71.

MorTon, J. (1969). Interaction of information in word recognition. Psychological Review, 76, 165-178.

Morton, J., \& Patterson, K. E. (1980). A new attempt at an interpretation, or, an attempt at a new interpretation. In M. Coltheart, K. E Patterson, \& J. C. Marshall (Eds.), Deep dyslexia (pp. 91-118). London: Routledge \& Kegan Paul.

OldField, R. C., \& WingField, A. (1965). Response latencies in naming objects. Quarterly Journal of Experimental Psychology, 4, 272-281.

QUINLAN, P. T. (1992). The MRC psycholinguistic database. London: Oxford University Press.

RiDDoCh, M. J., \&uMPHREYs, G. W. (1987). Object naming. In G. W. Humphreys \& M. J. Riddoch (Eds.), Visual object processing: A cognitive neuropsychological approach (pp. 107-143). Hove: Erlbaum.

Rochford, G., Williams, M. (1962). Studies in the development and breakdown of the use of names, Part I: The relation between nominal dysphasia and the acquisition of vocabulary in childhood. Part II: Experimental production of naming disorders in normal people. Journal of Neurology, Neurosurgery \& Psychiatry, 25, 222-233.

RochforD, G., Williams, M. (1965). Studies in the development and breakdown of the use of names, Part IV: The effects of word frequency. Journal of Neurology, Neurosurgery \& Psychiatry, 28 , 407-413.

Rubin, D. C. (1980). 51 properties of 125 words: A unit analysis of verbal behavior. Journal of Verbal Learning \& Verbal Behavior, 19 736-755.

Segui, J., Mehler, J., Frauenfelder, U., \& Morton, J. (1982). The word frequency effect and lexical access. Neuropsychologia, 2, 615-627.

SEYmour, P. H. K. (1979). Human visual cognition. London: CollierMacMillan.

Snodgrass, J. G., * VANDERWart, M. (1980). A standardized set of 260 pictures: Norms for name agreement, image agreement, familiarity, and visual complexity. Jourmal of Experimental Psychology: Human Learning \& Memory, 6, 174-215.

SPREEN, O. (1968). Psycholinguistic aspects of aphasia. Journal of Speech \& Hearing Research, 11, 467-480.

Stemberger, J. P., MacWhinney, B. (1986). Frequency and the lexical storage of regularly inflected words. Memory \& Cognition, $14,17-26$

Theios, J., AMrheiN, P. C. (1989). Theoretical analysis of the cog nitive processes of lexical and pictorial stimuli: Reading, naming, and visual and conceptual comparisons. Psychological Review, 96, 5-24.
Thorndike, E. L., LORGE, I. (1944). The teacher's word book of 30,000 words. New York: Teachers College Press, Columbia University.

Vitkovitch, M., Humphreys, G. W. (1991). Perseverant responding in speeded naming of pictures: It's in the links. Journal of Experimental Psychology: Leaming, Memory, \& Cognition, 17, 664680.

WHALEY, C. P. (1978). Word-nonword classification time. Journal of Verbal Learning \& Verbal Behavior, 17, 143-154.

WINGFIELD, A. (1968). Effects of frequency on identification and naming of objects. American Journal of Psychology, 81, 226-234.

ZiNGeSER, L. B., BERNot, R. S. (1988). Grammatical class and context effects in a case of pure anomia: Implications for models of language production. Cognitive Neuropsychology, 5, 473-516.

\section{NOTES}

1. Codability or name agreement (i.e., the proportion of responses that exactly match the target name) has been used as an independent variable in some previous studies. It is, however, dependent upon the data and might thus be regarded as a dependent rather than an independent variable. For that reason, we have not included it as an independent variable in any of the analyses reported here.

2. Kučera and Francis (1967) was preferred to the Thorndike-Lorge (1944) word count for the reasons discussed earlier. An alternative frequency measure taken from samples of written British English is provided by Johansson and Hofland (1989). For the sample of object names used in Experiments 1 and 2, the Johansson and Hofland frecuency correlates .903 with the Kučera and Francis frequency. However, 6 of the 26 object names in the Oldfield and Wingfield (1965) study are present in Kučera and Francis (1967) but missing from Johansson and Hofland (1989). When the analyses of Experiments $I$ and 2 were re-run using Johansson and Hofland frequencies, the pattern of results was the same as that reported here. Segui, Mehler, Frauenfelder, and Morton (1982) found a high correlation between subjective rankings of word frequency and Kučera and Francis (1967) values. Hence Kučera and Francis frequencies are used throughout

3. The formula is:

$$
z=\frac{R_{1}-R_{2}}{\sqrt{\frac{1}{N_{1}-3}+\frac{1}{N_{2}-3}}} .
$$

where $R_{1}$ and $R_{2}$ are the simple regression coefficients for the dependent variable of interest and the independent variables in the two experiments, and $N_{1}$ and $N_{2}$ are the numbers of items in the two experiments.

Data from Experiments 1 (Picture Naming) and 2 (Picture Classification)

\begin{tabular}{lccccccc}
\hline & $\begin{array}{c}\text { K-F } \\
\text { Frequency }\end{array}$ & $\begin{array}{c}\text { Age of } \\
\text { Acquisition }\end{array}$ & $\begin{array}{c}\text { Length } \\
\text { (Phonemes) }\end{array}$ & Imageability & Prototypicality & $\begin{array}{c}\text { Mean } \\
\text { Categorization } \\
\text { Latency } \\
\text { (Milliseconds) }\end{array}$ & $\begin{array}{c}\text { Mean } \\
\text { Naming } \\
\text { Latency } \\
\text { (Milliseconds) }\end{array}$ \\
\hline anchor & & & & Man-made & & & \\
axe & 15 & 4.88 & 4 & 5.61 & 2.83 & 1,074 & 898 \\
ball & 6 & 4.38 & 3 & 5.97 & 4.00 & 754 & 879 \\
ballon & 110 & 1.34 & 3 & 6.22 & 3.67 & 916 & 869 \\
basket & 10 & 2.03 & 5 & 5.83 & 2.92 & 782 & 758 \\
bell & 17 & 3.12 & 6 & 5.60 & 4.25 & 706 & 741 \\
book & 18 & 2.36 & 3 & 6.10 & 3.33 & 806 & 679 \\
cake & 193 & 1.83 & 3 & 5.91 & 3.92 & 702 & 681 \\
chair & 13 & 2.06 & 3 & 6.24 & 3.50 & 771 & 759 \\
cigarette & 66 & 1.86 & 2 & 6.10 & 4.17 & 576 & 664 \\
(1) & 25 & 3.62 & 7 & 6.45 & 2.67 & 897 & 1,096
\end{tabular}


APPENDIX (Continued)

\begin{tabular}{|c|c|c|c|c|c|c|c|}
\hline & $\begin{array}{c}\text { K-F } \\
\text { Frequency }\end{array}$ & $\begin{array}{c}\text { Age of } \\
\text { Acquisition }\end{array}$ & $\begin{array}{c}\text { Length } \\
\text { (Phonemes) }\end{array}$ & Imageability & Prototypicality & $\begin{array}{c}\text { Mean } \\
\text { Categorization } \\
\text { Latency } \\
\text { (Milliseconds) }\end{array}$ & $\begin{array}{c}\text { Mean } \\
\text { Naming } \\
\text { Latency } \\
\text { (Milliseconds) }\end{array}$ \\
\hline clock & 20 & 2.36 & 4 & 6.14 & 4.17 & 609 & 750 \\
\hline cup & 45 & 1.66 & 3 & 5.58 & 3.83 & 743 & 751 \\
\hline drum & 11 & 2.48 & 4 & 5.99 & 3.17 & 625 & 832 \\
\hline envelope & 21 & 3.93 & 7 & 5.54 & 2.75 & 659 & 811 \\
\hline fork & 14 & 2.24 & 3 & 5.98 & 3.75 & 713 & 821 \\
\hline glove & 9 & 3.12 & 4 & 5.96 & 3.16 & 902 & 880 \\
\hline iron & 43 & 3.88 & 3 & 5.61 & 2.83 & 631 & 762 \\
\hline key & 88 & 3.38 & 2 & 6.18 & 3.58 & 670 & 757 \\
\hline kite & 1 & 3.72 & 3 & 6.24 & 3.00 & 678 & 784 \\
\hline knife & 76 & 2.70 & 3 & 6.33 & 4.33 & 628 & 895 \\
\hline lamp & 18 & 2.72 & 4 & 5.75 & 3.67 & 618 & 796 \\
\hline pipe & 20 & 4.07 & 3 & 5.98 & 2.75 & 646 & 815 \\
\hline spoon & 6 & 1.97 & 4 & 5.84 & 3.83 & 787 & 888 \\
\hline table & 198 & 2.45 & 4 & 5.82 & 4.42 & 599 & 768 \\
\hline umbrella & 8 & 4.09 & 7 & 5.92 & 3.67 & 641 & 761 \\
\hline vase & 4 & 4.30 & 3 & 5.63 & 3.17 & 577 & 858 \\
\hline window & 119 & 2.28 & 5 & 6.02 & 3.42 & 682 & 950 \\
\hline$M$ & 43.48 & 2.92 & 3.88 & 5.95 & 3.51 & 718 & 811 \\
\hline$S D$ & 54.51 & .98 & 1.42 & .25 & .54 & & \\
\hline \multicolumn{8}{|c|}{ Natural } \\
\hline apple & 9 & 1.91 & 3 & 6.37 & 4.34 & 611 & 739 \\
\hline banana & 4 & 1.90 & 6 & 6.44 & 3.58 & 647 & 699 \\
\hline butterfly & 2 & 2.97 & 7 & 6.24 & 3.58 & 678 & 886 \\
\hline cat & 23 & 1.36 & 3 & 6.17 & 3.67 & 624 & 719 \\
\hline cow & 29 & 1.90 & 2 & 6.32 & 3.50 & 570 & 868 \\
\hline $\operatorname{dog}$ & 75 & 1.55 & 3 & 6.36 & 3.67 & 672 & 643 \\
\hline ear & 29 & 1.82 & 2 & 5.97 & 2.67 & 734 & 677 \\
\hline elephant & 7 & 2.85 & 6 & 6.16 & 3.17 & 618 & 779 \\
\hline eye & 122 & 2.00 & 1 & 6.03 & 2.67 & 819 & 632 \\
\hline fish & 35 & 2.61 & 3 & 6.15 & 3.50 & 624 & 678 \\
\hline flower & 23 & 2.15 & 4 & 6.18 & 4.67 & 635 & 878 \\
\hline frog & 1 & 3.15 & 4 & 6.17 & 3.67 & 660 & 706 \\
\hline horse & 117 & 2.67 & 3 & 6.24 & 3.42 & 609 & 771 \\
\hline leaf & 12 & 2.61 & 3 & 6.08 & 4.42 & 659 & 729 \\
\hline lemon & 18 & 3.06 & 5 & 6.32 & 3.58 & 600 & 924 \\
\hline lion & 17 & 2.82 & 3 & 6.26 & 3.17 & 689 & 770 \\
\hline pig & 8 & 2.94 & 3 & 6.35 & 2.92 & 576 & 862 \\
\hline rabbit & 11 & 2.61 & 5 & 6.11 & 3.58 & 561 & 726 \\
\hline snake & 44 & 3.52 & 4 & 6.27 & 3.00 & 625 & 707 \\
\hline strawberry & 0 & 3.61 & 7 & 6.31 & 3.33 & 677 & 1,064 \\
\hline tree & 59 & 2.03 & 3 & 6.22 & 4.92 & 634 & 776 \\
\hline$M$ & 30.71 & 2.48 & 3.81 & 6.22 & 3.57 & 644 & 773 \\
\hline$S D$ & 35.26 & .63 & 1.63 & .12 & .6 & & \\
\hline Grand $M$ & 37.90 & 2.73 & 3.85 & 6.07 & 3.54 & 686 & 794 \\
\hline$S D$ & 47.10 & .86 & 1.5 & .25 & .56 & & \\
\hline Range & $0-198$ & $1.34-4.88$ & $1-7$ & 5.54-6.45 & $2.67-4.92$ & & \\
\hline
\end{tabular}

(Manuscript received November 20, 1991;

revision accepted for publication April 14, 1992.) 